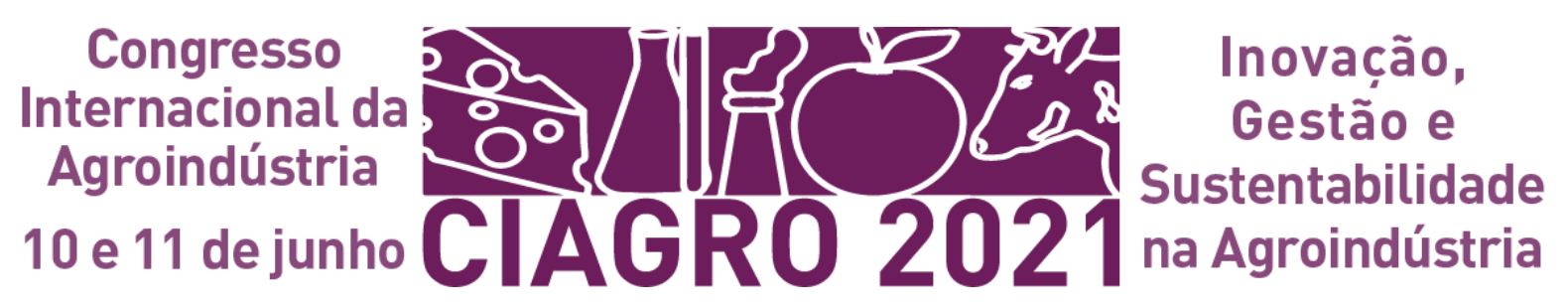

UTILIZAÇÃO DOS ÓLEOS ESSENCIAIS NOS ALIMENTOS: UMA REVISÃO

\author{
USO DE ACEITES ESENCIALES EN LOS ALIMENTOS: REVISIÓN
}

USE OF ESSENTIAL OILS IN THE FOODS: A REVIEW

Cássia Duarte Oliveira ${ }^{1}$; Gabriela Fontes Alvarenga ${ }^{2}$; Anderson Henrique Venâncio ${ }^{3}$ Bruna Azevedo Balduino $^{4}$;
Maria das Graças Cardoso

DOI: $\underline{\text { https://doi.org/10.31692/IICIAGRO.0255 }}$

\begin{abstract}
RESUMO
Os óleos essenciais são metabólitos secundários de plantas constituídos de terpenos, terpenóides e fenilpropanoides. Devido a essa constituição, eles possuem propriedades biológicas de interesse, como antioxidante, antimicrobiana, anti-inflamatória, inseticida, anticâncer e diversas outras. Esses óleos são insolúveis em água, voláteis e possuem sabor forte e característico. Porém, essas características limitantes podem afetar a incorporação desses óleos nos alimentos. No entanto, estudos vêm sendo realizados, e atrelados ao desenvolvimento tecnológico, alternativas para essas limitações vêm sendo descobertas, como a utilização de nanoemulsões, nanocápsulas, micelas poliméricas, lipossomas, partículas de lipídeos, polissacarídeos, nano e micropartículas poliméricas. Assim, neste contexto, o objetivo deste trabalho foi realizar uma revisão de literatura sobre os óleos essenciais e suas potencialidades para utilização na indústria de alimentos devido suas atividades antimicrobianas e antioxidantes. Bem como, exemplificar alternativas de aplicação desses óleos puros e submetidos a diferentes tecnologias para facilitar sua incorporação em diversos alimentos. Para realizar a pesquisa foram utilizadas as seguintes palavras chave: essential oil, antioxidante activity, animicrobial activity e encapsulation nas bases de dados: Science direct, Scielo e Web of Science. Como resultados foi constatada a importância da utilização dos óleos essenciais em diversas áreas nos setores alimentícios, visto que o mesmo pode ser empregado como alternativa aos aditivos sintéticos tradicionais. Seu uso em embalagens com liberação controlada e na formulação durante o desenvolvimento de novos produtos vem sendo bastante estudado. $\mathrm{O}$ emprego dessas tecnologias melhora a estabilidade dos óleos, reduz os impactos organolépticos nos alimentos, e confere a liberação gradativa, favorecendo suas propriedades como antioxidante e antimicrobiano nos alimentos, aumentando a vida útil e reduzindo a utilização de aditivos sintéticos.
\end{abstract}

Palavras-Chave: Antimicrobiano, antioxidante, encapsulação, metabólitos secundários.

\title{
RESUMEN
}

Los aceites esenciales son metabolitos secundarios de plantas compuestos por terpenos, terpenoides y fenilpropanoides. Debido a esta constitución, poseen propiedades biológicas de interés, como

\begin{tabular}{|c|c|c|c|c|c|c|c|c|}
\hline $\begin{array}{l}1 \text { Programa de Pós-Graduação } \\
\text { cassiaduartemg2@hotmail.com }\end{array}$ & em & Ciência & dos & Alimentos, & Universidade & Federal & de & Lavras, \\
\hline $\begin{array}{l}2 \text { Programa de Pós-Graduação } \\
\text { gabrielafalvarenga@gmail.com }\end{array}$ & em & Ciência & dos & Alimentos, & Universidade & Federal & de & Lavras, \\
\hline $\begin{array}{l}3 \text { Programa de Pós-Graduação } \\
\text { andeson123dfgh21@gmail.com }\end{array}$ & em & Ciência & dos & Alimentos, & Universidade & Federal & de & Lavras, \\
\hline $\begin{array}{l}4 \text { Programa de Pós-Graduação } \\
\text { brunaazevedo.94@hotmail.com }\end{array}$ & em & Ciência & dos & Alimentos, & Universidade & Federal & de & Lavras, \\
\hline
\end{tabular}




\section{UTILIZAÇÃO DOS ÓLEOS ESSENCIAIS NOS ALIMENTOS: UMA REVISÃO}

antioxidantes, antimicrobianas, antiinflamatorias, insecticidas, anticancerígenas y varias otras. Estos aceites son insolubles en agua, volátiles y tienen un sabor fuerte y característico. Sin embargo, estas características limitantes pueden afectar la incorporación de estos aceites en los alimentos. Sin embargo, se han realizado estudios, y ligados al desarrollo tecnológico, se han descubierto alternativas a estas limitaciones, como el uso de nanoemulsiones, nanocápsulas, micelas poliméricas, liposomas, partículas lipídicas, polisacáridos, nano y micropartículas poliméricas. Así, en este contexto, el objetivo de este trabajo fue realizar una revisión de la literatura sobre los aceites esenciales y su potencial de uso en la industria alimentaria por sus actividades antimicrobianas y antioxidantes. Así como, ejemplificar alternativas para la aplicación de estos aceites puros y sometidos a diferentes tecnologías para facilitar su incorporación en diferentes alimentos. Para realizar la investigación se utilizaron las siguientes palabras clave: aceite esencial, actividad antioxidante, actividad animicrobiana y encapsulación en las bases de datos: Science direct, Scielo y Web of Science. Como resultado, se comprobó la importancia del uso de aceites esenciales en varias áreas del sector alimentario, ya que se puede utilizar como alternativa a los aditivos sintéticos tradicionales. Su uso en envases con liberación controlada y en la formulación durante el desarrollo de nuevos productos ha sido ampliamente estudiado. El uso de estas tecnologías mejora la estabilidad de los aceites, reduce los impactos organolépticos en los alimentos y proporciona una liberación gradual, favoreciendo sus propiedades como antioxidantes y antimicrobianos en los alimentos, aumentando la vida útil y reduciendo el uso de aditivos sintéticos.

Palabras Clave: Antimicrobiano, antioxidante, encapsulado, metabolitos secundarios.

\section{ABSTRACT}

Essential oils are secondary metabolites of plants made up of terpenes, terpenoids and phenylpropanoids. Due to this constitution, they have biological properties of interest, such as antioxidant, antimicrobial, anti-inflammatory, insecticide, anticancer and several others. These oils are insoluble in water, volatile and have a strong and characteristic flavor. However, these limiting characteristics can affect the incorporation of these oils in food. However, studies have been carried out, and linked to technological development, alternatives to these limitations have been discovered, such as the use of nanoemulsions, nanocapsules, polymeric micelles, liposomes, lipid particles, polysaccharides, nano and polymeric microparticles. Thus, in this context, the objective of this work was to carry out a literature review on essential oils and their potential for use in the food industry due to their antimicrobial and antioxidant activities. As well as, exemplify alternatives for applying these pure oils and subjected to different technologies to facilitate their incorporation into different foods. To carry out the research, the following keywords were used: essential oil, antioxidant activity, animicrobial activity and encapsulation in the databases: Science direct, Scielo and Web of Science. As a result, it was verified the importance of using essential oils in several areas in the food sectors, since it can be used as an alternative to traditional synthetic additives. Its use in packaging with controlled release and in the formulation during the development of new products has been extensively studied. The use of these technologies improves the stability of oils, reduces the organoleptic impacts on foods, and provides gradual release, favoring their properties as antioxidants and antimicrobials in foods, increasing the shelf life and reducing the use of synthetic additives.

Keywords: Antimicrobial, antioxidant, encapsulation, secondary metabolites.

\section{INTRODUÇÃO}

Durante os últimos anos observa-se uma mudança no comportamento dos consumidores de alimentos industrializados que exigem, cada vez mais, alimentos naturais e seguros para a saúde. Este fato vem impulsionando uma transformação no desenvolvimento de novos produtos com a utilização de matérias-primas naturais em suas formulações. Uma das alternativas para atender a essa demanda de mercado é o uso de aditivos naturais como substituintes dos tradicionais aditivos sintéticos, sendo os óleos essenciais uma opção para 
isso (RIBEIRO-SANTOS et al., 2018; HASSOUN; ÇOBAN, 2017).

De acordo com Organização internacional de padronização (ISO - International Organization for Standardization), óleo essencial é um produto obtido a partir de uma matéria-prima natural de origem vegetal, por destilação a vapor, por processos de extração mecânica do epicarpo de frutas cítricas, ou por destilação a seco, seguido da separação da fase aquosa, se houver, por processos físicos, podendo também ser tratado fisicamente sem que ocorra alterações da sua composição (SHARMA et al., 2021).

Os óleos essenciais são constituídos de uma mistura complexa de compostos poucos solúveis em água, como terpenos, terpenóides e fenilpropanóides. Tanto os terpenos, terpenóides e os fenilpropanóides são formados a partir do metabolismo da glicose, como demonstrado na Figura 01. Os terpenos são hidrocarbonetos compostos por várias unidades de isopreno, e podem ser classificadas pelo número de unidades de isopreno na molécula (mono, sesqui e diterpenos). Os terpenóides são terpenos contendo oxigênio e podem ser classificados em álcoois, ésteres, aldeídos, cetonas, éteres e fenóis. Já os fenilpropanóides, como o eugenol e o cinamaldeído, são derivados do aminoácido fenilalanina (RIBEIRO-SANTOS et al., 2018; STEVANOVIĆ et al., 2018; HASSOUN; ÇOBAN, 2017; DIMA; DIMA, 2015). 


\section{UTILIZAÇÃO DOS ÓLEOS ESSENCIAIS NOS ALIMENTOS: UMA REVISÃO}

Figura 01: Metabolismo da glicose, vias do ácido chiquímico e acetil-CoA

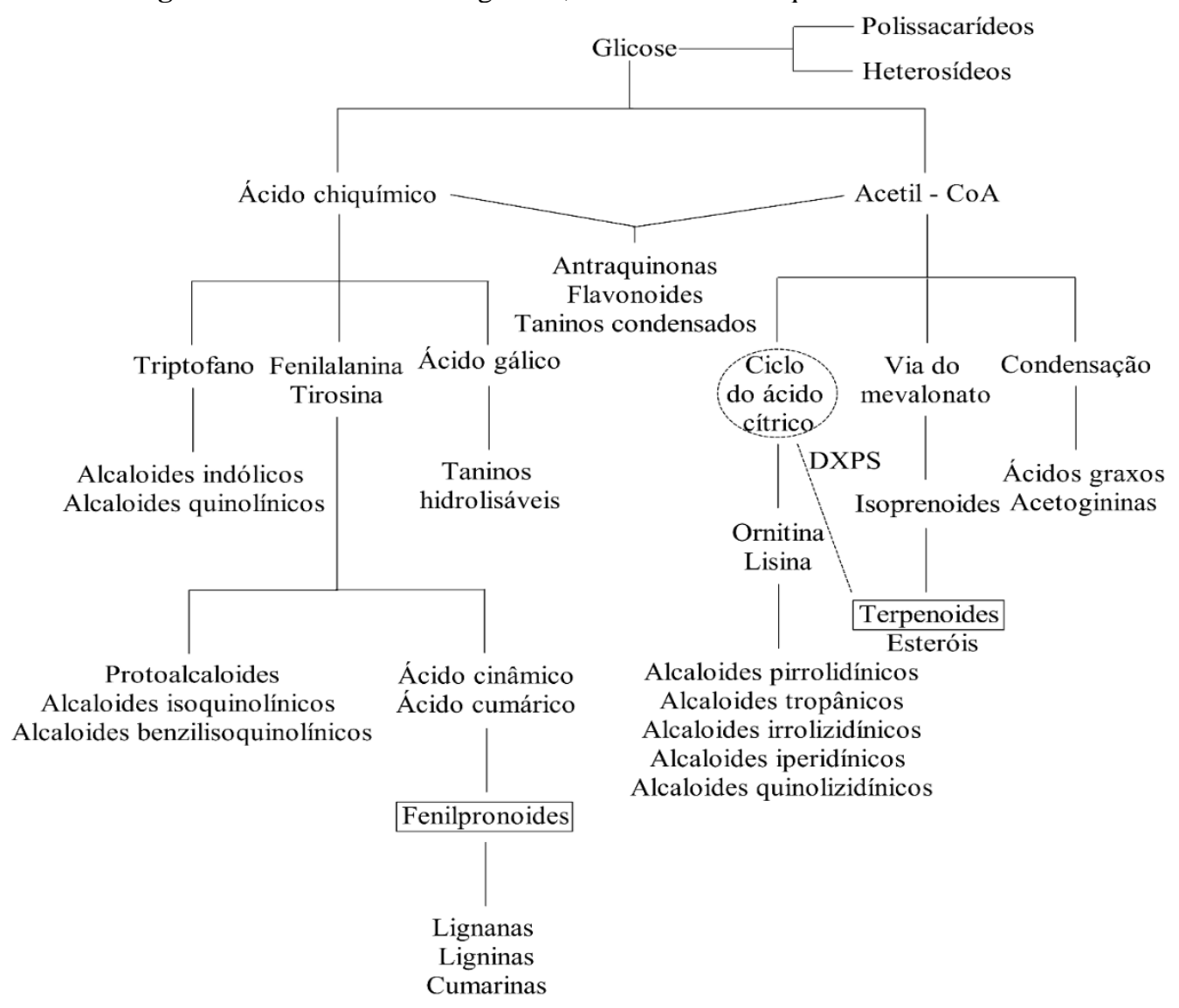

Fonte: Simões et al. (2017).

Nas plantas esses compostos são sintetizados como metabólitos secundários para fornecer proteção contra agentes externos, como luz UV, herbívoros, insetos e patógenos. Eles são obtidos a partir de três vias biossintéticas diferentes: a via metileritritol-fosfato para mono-terpenos e diterpenos, a via do mevalonato para sesquiterpenos e a via do ácido chiquímico para fenilpropanóides. São produzidos por diferentes partes das plantas, e podem ser extraídos de diferentes materiais vegetais, como folhas, cascas, caules, raízes, flores e frutas. No total, mais de 3000 tipos óleos essenciais são conhecidos, dos quais apenas 300 são de interesse comercial para aplicações em alimentos ou outras indústrias (RIBEIRO-SANTOS et al., 2018; HASSOUN; ÇOBAN, 2017).

Os óleos essenciais têm sido usados há séculos como fragrâncias de perfumes, na culinária como aromatizantes e na medicina popular. Atualmente, o interesse nesses produtos está associado principalmente as suas diferentes propriedades biológicas, como antioxidante, antimicrobiana, antitumoral, analgésica, inseticida, antidiabética e anti-inflamatória. Devido a essas características, a indústria de alimentos, cada vez mais, está empregando-os na formulação de produtos ou incorporando-os em embalagens. Sendo que um óleo essencial ideal para indústria de alimentos seria aquele que está disponível em grandes volumes, como 
co-produto e que é geralmente reconhecido como seguro (GRAS) porque já faz parte da dieta humana típica há anos (RIBEIRO-SANTOS et al., 2018; STEVANOVIĆ et al., 2018; TOMAR et al., 2018).

Entretanto, a utilização dos óleos essenciais de forma industrial pode apresentar algumas limitações como a grande variabilidade da composição química, interações com a matriz alimentar, toxicidade, características sensórias peculiares, necessidade de padronização prévia da forma de aplicação no produto, natureza volátil, susceptibilidade a oxidação e riscos a biodiversidade ecológica. Sendo necessário o desenvolvimento de tecnologias e de pesquisas para encontrar alternativas que superem essas barreiras (STEVANOVIĆ et al., 2018; RIBEIRO-SANTOS et al., 2018).

Uma dessas alternativas é a encapsulação ou produção de nanoemulsões dos óleos, essas tecnologias contribuem para melhorar a estabilidade, prolongar a vida de prateleira, direcionar a ação dos compostos bioativos, melhora a biodisponibilidade, facilitar a incorporação no alimento e a mistura com outros ingredientes e pode mascarar a percepção de odores fortes. Outra opção é a incorporação do óleo essencial em embalagens, com o desenvolvimento de embalagens ativas, que permitem a interação entre o alimento e a embalagem, promovendo atividade antimicrobiana e antioxidante, sem a necessidade do óleo ser incorporado ao alimento (STEVANOVIĆ et al., 2018; RIBEIRO-SANTOS et al., 2017; PRAKASH et al., 2018).

Assim, neste contexto, o objetivo deste trabalho foi realizar uma revisão de literatura sobre os óleos essenciais e suas potencialidades para utilização pela indústria de alimentos devido suas atividades antimicrobianas e antioxidantes. Bem como, exemplificar alternativas de aplicação desses óleos puros e submetidos a diferentes tecnologias para facilitar sua incorporação em diversos alimentos.

\section{METODOLOGIA}

Para a seleção dos artigos científicos, utilizou-se as seguintes bases de dados: Science direct, Scielo e Web of Science, considerando os artigos publicados nos últimos 10 anos (2011-2021) e utilizando como termos de buscas essential oil, antioxidante activity, animicrobial activity e encapsulation. Foram selecionados para essa revisão somente os artigos que possibilitaram aos autores alcançar os objetivos estabelecidos anteriormente. 
UTILIZAÇÃO DOS ÓLEOS ESSENCIAIS NOS ALIMENTOS: UMA REVISÃO

\section{DESENVOLVIMENTO}

\section{Atividade antimicrobiana dos óleos essenciais}

Muitos óleos essenciais apresentam propriedade antimicrobiana que pode variar de acordo com a composição química. Essa composição também determina o modo de ação desses óleos sobre as bactérias. Dessa forma, como a composição dos óleos essenciais é bem variada, a atividade antimicrobiana não pode ser atribuída a um único mecanismo de ação, uma vez que diferentes grupos podem exercer diferentes ações em diferentes regiões das células microbianas (PATEIRO et al., 2021).

Os óleos essenciais podem provocar efeitos bactericidas e bacteriostáticos, sendo o primeiro relacionado com a morte das bactérias e o segundo com a inibição do crescimento, de forma que as células microbianas possam recuperar a capacidade reprodutiva (FALLEH et al., 2020; PATEIRO et al., 2021).

A atividade microbiana dos óleos essenciais não é a mesma sobre as bactérias gramnegativas e positivas e isso ocorre devido a limitação da membrana externa nas gramnegativas à entrada de componentes hidrofóbicos nas células. Porém, estudos mostram que óleos essenciais como canela, cravo da índia e orégano possuem a mesma eficiência sobre as duas bactérias. Os compostos fenólicos são os principais responsáveis pelos mecanismos de ação dos óleos essenciais, e a atividade microbiológica está relacionada com a posição do grupo hidroxila (PATEIRO et al., 2021).

O mecanismo de ação dos óleos essenciais depende da concentração e dos constituintes químicos. Os diferentes constituintes podem atuar sob diferentes mecanismos e ter como alvos diferentes microrganismos como bactérias gram-positivas e negativas, bolores e leveduras, uma vez que esses microrganismos diferem na composição das membranas celulares. Diversos autores atribuem o mecanismo de ação dos óleos essenciais à capacidade de penetrar nas membranas externas das células bacterianas e nas membranas citoplasmáticas para o interior da célula, desintegrando as estruturas celulares e tornando-as mais permeáveis aos óleos essenciais. Assim, os mecanismos comuns de ação dos óleos essenciais em células bacterianas são: alteração do ácido graxo na membrana externa, danificação da membrana citoplasmática, depleção da força motriz do próton e vazamento de metabólitos e íons vitais às células (RAO; CHEN; MCCLEMENTS, 2019).

\section{Atividade antioxidante dos óleos essenciais}

Alguns óleos essenciais apresentam maior atividade antioxidante do que outros e isso se deve aos constituintes presentes em cada óleo. Um exemplo é o óleo essencial de alecrim 
que possui capacidade quelante e antioxidante. Esse óleo possui como constituintes: 1,8cineol, $\alpha$-pineno, cânfora, acetato de bornil, borneol, canfeno, $\alpha$-terpineol, limoneno, $\beta$ pineno, $\beta$-cariofileno e mirceno (CHÁVEZ-GONZÁLEZ et al., 2016, BORGES et al., 2019).

Essa capacidade antioxidante e quelante foi avaliada por meio de um estudo que mostrou a capacidade de absorção de radicais de oxigênio por $\beta$-pineno, limoneno, $\gamma$ terpineno, linalol, terpin-4-ol, $\alpha$-terpineol e $\beta$-cariofileno, além da atividade quelante dos íons $\mathrm{Fe}^{2+}$ por $\alpha$-pineno, canfeno e 1,8-cineol (CUTILLAS et al., 2018, BORGES et al., 2019). Outros estudos também mostraram que o óleo essencial de alecrim inibiu a peroxidação lipídica induzida pela reação de Fenton com $\mathrm{Fe}^{2+}$, ascorbato e $\mathrm{Fe}^{2+}$ e $\mathrm{H}_{2} \mathrm{O}_{2}$ (BOZIN et al., 2007; BORGES et a., 2019).

De acordo com Pateiro et al. (2018), a atividade antioxidante dos compostos fenólicos acontece em três fases distintas, iniciação, propagação e término. O grupo hidroxila doa o hidrogênio inativando os radicais livres da oxidação dos ácidos graxos insaturados. A oxidação causa a formação de novos radicais que são incapazes de extrair átomos de hidrogênio de lipídeos insaturados. Os radicais livres formados podem reagir com espécies radicalares semelhantes ou outros radicais lipídicos, o que resultará em espécies não radicalares. As propriedades redox dos compostos fenólicos se devem a capacidade de doação de um elétron ao radical livre, o que o caracteriza um antioxidante eficaz, evitando a oxidação de outros compostos (PATEIRO et al., 2018).

A capacidade antioxidante dos óleos essenciais deve ser avaliada por diferentes métodos. Sarikurkcu et al. (2015) avaliaram essa capacidade antioxidante do óleo essencial de orégano de 2 espécies diferentes (Vulgare e Hirtum) por meio de sete ensaios: eliminação de radicais livres (DPPH e ABTS), poder redutor (FRAP e CUPRAC), $\beta$ - caroteno / ácido linoléico, quelante de metal e ensaios de fosfomolibdênio.

Para serem considerados bons eliminadores de radicais livres, como o DPPH e o ABTS, os óleos essenciais devem possuir em sua constituição eliminadores eficazes desses radicais, como o timol e o carvacrol, que são compostos fenólicos. O poder redutor dos óleos essenciais é utilizado como indicador significativo do potencial atividade antioxidante, e isso pode ser observado por meio da capacidade dos constituintes dos óleos em reduzir os íons ferro e cúprico. $\mathrm{O}$ método de branqueamento do $\beta$ caroteno é realizado para avaliar a capacidade do componente em estudo inibir a peroxidação lipídica. Isso porque o $\beta$ caroteno é oxidado pelos radicais formados pela oxidação do ácido linoleico e o sistema perde seu cromóforo e a cor laranja característica. Todos esses testes são monitorados espectrofotometricamente. Com relação ao efeito quelante dos íons ferrosos, essa análise 
avalia a capacidade do óleo essencial em interferir na formação do $\mathrm{Fe}^{2+}$ e do complexo ferrozine, e caso esse óleo tenha efeito quelante, ele irá capturar o $\mathrm{Fe}^{2+}$ antes do ferrozine. No ensaio fosofomolibidênio, o teste é baseado na redução do Mo (VI) a Mo (V) por meio das substâncias antioxidantes (SARIKURKCU et al., 2015). Nesse estudo, foi observado que houve diferença nos resultados dos métodos antioxidantes das diferentes espécies óleo essencial de orégano, sendo que a espécie Vulgare possuiu maior eliminação de radicais livres, poder de redução e branqueamento do $\beta$-caroteno, enquanto o óleo de orégano da espécie Hirtum apresentou maior capacidade quelante de metais e sobre o ensaio de fosfomolibidênio.

\section{Uso dos óleos essenciais nos alimentos}

Os óleos essenciais vêm sendo incorporados aos alimentos pelo fato de conferirem propriedades desejáveis, como antioxidante, antibacteriano, antifúngico, e outras, além de ser um produto natural que aumenta a vida de prateleira dos alimentos. Assim, como no Quadro 01, o uso em diversos alimentos vem sendo estudado. 
Quadro 01: Uso de óleos essenciais em alimentos.

\begin{tabular}{|c|c|c|}
\hline Óleo essencial & Alimentos & Referências \\
\hline $\begin{array}{l}\text { Orégano mexicano } \\
\text { (Lippia berlandieri) }\end{array}$ & Pão & SÁNCHEZ et al., 2015 \\
\hline $\begin{array}{c}\text { Tomilho vermelho } \\
\text { (Thymus zygis L.); } \\
\text { Casca de canela } \\
\text { (Cinnamomum zeylanicum); } \\
\text { Orégano } \\
\text { (Origanum vulgare L.) }\end{array}$ & $\begin{array}{c}\text { Hambúrgueres de salmão e } \\
\text { algas marinhas }\end{array}$ & DOLEA et al., 2018 \\
\hline $\begin{array}{c}\text { Folha de canela } \\
\text { (Cinnamomum zeylanicum) }\end{array}$ & Suco de laranja & $\begin{array}{c}\text { SÁNCHEZ-RUBIO et } \\
\text { al., } 2018\end{array}$ \\
\hline $\begin{array}{c}\text { Saxífraga } \\
\text { (Pimpinella saxifraga) }\end{array}$ & Queijo & KSOUDA et al., 2019 \\
\hline $\begin{array}{l}\text { Folha de limão ciciliano } \\
\qquad \text { (Citrus limon) }\end{array}$ & Queijo ricota & $\begin{array}{l}\text { FANCELLO et al., } \\
2020\end{array}$ \\
\hline $\begin{array}{c}\text { Hortelã-pimenta } \\
\text { (Mentha piperita L.) }\end{array}$ & Linguiça de porco & ŠOJIĆ et al., 2020 \\
\hline $\begin{array}{c}\text { Litsea cubeba } \\
\text { (Litsea cubeba (Lour.) } \\
\text { Pers. })\end{array}$ & Sucos de vegetais & DAI et al., 2021 \\
\hline $\begin{array}{c}\text { Capim-limão } \\
\text { (Cymbopogon citratus) }\end{array}$ & Frango & DEWI et al., 2021 \\
\hline $\begin{array}{c}\text { Tomilho } \\
\text { (Thymus vulgaris) }\end{array}$ & $\begin{array}{c}\text { Salsicha de carne de cavalo } \\
\text { defumada }\end{array}$ & HUANG et al., 2021 \\
\hline $\begin{array}{c}\text { Orégano } \\
\text { (Origanum vulgare) }\end{array}$ & Salsicha cozida fermentada & OZAKI et al., 2021 \\
\hline
\end{tabular}

Fonte: Própria (2021)

No entanto, devido ao odor intenso, alta volatilidade e instabilidade devido à presença de oxigênio, luz e temperatura, a utilização dos óleos essenciais na indústria de alimentos se torna limitado (RADÜNZ et al., 2019). 


\section{UTILIZAÇÃO DOS ÓLEOS ESSENCIAIS NOS ALIMENTOS: UMA REVISÃO}

\section{Alternativas às limitações dos óleos essenciais}

Por serem conhecidos pelas atividades antimicrobianas, os óleos essenciais não são muito utilizados nos alimentnos como conservantes devido à necessidade de utilização de altas concentrações para agir sobre os microrganimos nos alimentos e sua capacidade de alterar as características sensoriais dos alimentos em que são adicionados, excedendo o limite de sabor aceitável pelos consumidores (PINELLI et al., 2021). Assim, muitas alternativas vêm sendo utilizadas para superar essas limitações quando incorporados aos alimentos.

Atualmente, estudos sobre os óleos essenciais encapsulados vem se destacando. Isso porque a encapsulação pode melhorar a estabilidade desses óleos durante o processamento térmico e armazenamento, melhorar a atividade farmacológica e aumentar a solubilidade em água e a aplicação desses metabólitos secundários nos diversos setores em que podem ser utilizados como alimentício, de cosméticos, agricultura, fármacos e microbiológico (DE MATOS et al., 2019; FRAJ et al., 2019).

Existem diversos sistemas de entrega que podem ser utilizados nos óleos essenciais como micelas poliméricas, lipossomas, nanoemulsões, partículas de lipídeos, polissacarídeos, nano e micropartículas poliméricas (PIMENTEL-MORAL et al., 2016; FRAJ et al., 2019).

\section{Alternativas para diminuir as limitações do uso de óleos essenciais em alimentos}

Diversas metodologias podem ser utilizadas para melhorar as limitações dos óleos enssiancias, com o intuito de incorporá-los aos alimentos. Dentre essas metodologias, destacase a encapsulação, em escala nanométrica, nanoemulsão e lipossomas.

O encapsulamento é aplicado em ingredientes alimentícios, com o objetivo de protegêlos das condições adversas relaciondas com o processamento de alimentos. Muitos ingredeintes que são adiconados aos alimentos, como compostos aromáticos, óleos essenciais e vitaminas são sensíveis às condições de processamento, como a utilização de temperaturas elevadas. Isso pode causar perda de qualidade desses ingredientes devido à volatilização, oxidação lipídica e outros efeitos provocados pela luz e umidade Assim, os mateirias mais utilizados para o encapsulamento desses ingredientes são carboidratos, lipídeos e proteínas, e são empregados em vários processos como secagem por spray, resfriamento por spray e liofilização (DIMOPOULOS et al., 2021).

A utilização da encapsulação de óleos essiciais aumenta a estabilidade e a biodisponibilidade dos compostos bioativos, com o intuito de garantir o alcance dos sistemasalvo, além de permitir o controle da liberação dos compostos encapsulados Os óleos essenciais encapsulados possuem diversas aplicações na área de alimentos. Isso porque o 
encapsulamento é utilizado para superar problemas relacionados com a degradação dos compostos voláteis e também aplicação em matrizes alimentares para conservação. As principais aplicaçõe dos óleos essenciais encapsulados nos aliemtnos se devem à atividade antimicrobina e antioxidante desses óleos (RAZOLA-DÍAZ et al., 2021).

Rosa et al. (2020) realizaram um estudo sobre óleos essenciais de orégano e tomilho encapsulados em nanocápsulas de zeína. Essas nanocápsulas foram avaliadas quanto a sua atividade antioxidante por meio dos testes de remoção do radical DPPH e ABTS e FRAP. Os resultados para a capacidade antioxidante por DPPH, ABTS e FRAP foram para as nanocápsulas contendo óleo essencial de orégano 0,$42 ; 1,88$ e 0,24 e para as nanocápsulas contendo óleo essencial de tomilho de 0,$49 ; 1,38$ e 0,23. Foi possível observar que as nanopartículas contendo óleos essenciais inibiram os radicais livres DPPH e ABTS e atuaram como antioxidante reduzindo íons de ferro (FRAP), e isso está diretamente relacionado com a presença de compostos fenólicos nos óleos essenciais, como o timol e o carvacrol, conhecidos como antioxidantes primários, que quebram a cadeia e eliminam radicais livres com eficácia (PATEIRO et al., 2018; ROSA et al., 2020).

Ainda sobre esse estudo, além de avaliar a atividade antioxidante das nanocápsulas contendo óleo essencial, foi realizada a incorporação dessas nanocápsulas em pães para avaliar a atividade antimicrobiana. Verificou-se que essa incorporação aumentou a vida útil dos pães em um período de 21 dias, sendo observada a ausência de colônias de bolores e leveduras, que são os principais microrganismos que se desenvolvem em pães. As nanocápsulas de zeína foram capazes de proteger os óleos essenciais, que não se degradaram com o processo de cocção do pão a $200{ }^{\circ} \mathrm{C}$, mostrando que essas nancápsulas são altamente estáveis termicamente. Quando os óleos permanecem intactos, podem proteger os pães dos bolores e leveduras.

As nanoemulsões são dispersões coloidais, de água em óloe ou óleo em água, que possuem tamanho de partícula inferior a $200 \mathrm{~nm}$. Também apresentam como características serem translúcidas ou transparentes, estáveis termodinamicamente e resistentes à agregação, quando comparadas com as emulsões convencionais. Além disso, podem ser utilizadas para encapsular compostos hidrfóbicos, que serão incorporados aos alimentos (HASANIJAVANMARDI; FALLAH; ABBASVALI, 2021).

A utilização de nanoemulsões é outra metodologia empregada para melhorar as características de baixa estabilidade e insolubildiade em água dos óleos essenciais. Um exemplo é a produção de nanoemulsões por meio da homogeneização de alta pressão, que produz emulsões em nanoescalas, não dependendo do equilírio hidrofílico-lipofílico dos 


\section{UTILIZAÇÃO DOS ÓLEOS ESSENCIAIS NOS ALIMENTOS: UMA REVISÃO}

componentes, sendo obtidas partículas pequenas e uniformes, com boa estabilidade (LIU et al., 2021).

Sun et al. (2021) estudaram nanoemulsões de óleo essencial de lavanda, e incorporaram à matrizes de gelatina para a preparação de filmes com propriedades antioxidantes e antimicrobianas. Esses filmes foram aplicados a tomates cereja para auxiliar na preservação. Por meio dos ensaios de eliminação dos radicais DPPH e ABTS observou-se que os filmes apresentaram forte capacidade de eliminação desses radicais livres, com correlação positiva com o teor de óleo essencial de lavanda, o que favorece sua utilização em filmes de gelatina empregados para retardar a deterioração oxidativa de alimentos e manter o frescor. Os filmes contendo óleo essencial de lavanda também apresentaram atividade antibacteriana sobre as bactérias Staphylococcus aureus, Escherichia coli e Listeria monocytogenes e essa atividade também aumentou com o aumento do teor de óleo essencial adicionado. Esse óleo causou colapso estrutural e encolhimento das bactérias, levando-as à morte. Dessa forma, a utilização do óleo essencial de lavanda inibiu o crescimento das bactérias, prolongando a vida útil dos tomates.

Bedoya-Serna et al. (2018) realizaram um estudo sobre nanoemulsão contendo óleo essencial de orégano e aplicaram em queijo Minas Padrão com o objetivo de avaliar a atividade antifúngica. Os autores observaram que houve inibição de três espécies de fungos Cladosporium sp., Fusarium sp. e Penicillium sp. A eficácia do óleo essencial nanoemulsionado sobre os fungos foi dependente da quantidade de nanoemulsão, do tempo de imersão das fatias e da temperatura de armazenamento.

Destaca-se também os lipossomas, que são vesículas fechadas com estrutura de bicamadas fosfolipídicas, que separam o ambiente aquático circundante. Os lipossomas possuem tamanho de partícula variando de $10 \mathrm{~nm}$ a vários micrômetros. As bicamdas são compostas por lipídeos anfifílicos que possuem cabeça hidrofílica e duas caudas hidrofóbicas. A cabeça hidrofílica é o ácido fosfórico, que se encontra ligado a uma molécula solúvel em água, enquanto as caudas hidrofóbicas são formadas por duas cadeias de ácidos graxos de 1024 átomos de carbono e de 0-6 duplas ligações em cada cadeia (LIU et al., 2020).

Quando em meio aquoso, os fosoflipídeos são dispesos, de forma que a cauda hidrofóbica permaneça em contato com o ambiente polar e proteja o meio aquoso. Interações de Van der Waals e ligações de hidrogênio entre os fosfolipídeos e as moléculas de água ajudam a organizar os fosfolipédeos em vesículas fechadas de duas camadas, facilitando o transporte de moléculas hidrofóbicas e hidrofílicas. Nos lipossomas, os principais materiais de parede utilizados são fosfatidilcolina, fosfatidiletanolamina, fosfatidilserina e 
fosfatidilglicerol, sendo os fosfolipídeos naturais, como a lecitina (fosfatidilcolina) muito empregada na área de alimentos (LIU et al., 2020).

Segundo Liu e colaboradores (2020), os lipossomas são aplicados nos alimentos para encapsular compostos ou aditivos alimentares, com o ojetivo de aumentar a biodisponibilidade de componentes nutricionais, controlar a liberação de sabores e aumentar a vida útil dos produtos.

Wu et al. (2019) utilizaram lipossomas contendo óleo essencial de louro, que possui propriedade antimicrobiana e antioxidante, e nanopartículas de prata, que é um agente antimicrobiano. Esses lipossoamas foram incorporados em filmes de polietileno para embalar carnes de porco. O óleo essencial foi incorporado na bicamada fosfolipídica do lipossoma devido a sua lipossolubilidade, enquanto as nanopartílas de prata foram aprisionadas no núcleo hidrofílico do lipossoma. Observou-se que os lipossomas apresentaram boas propriedades antioxidantes e os filmes incorporados com os lipossomas apresentaram boa atividade antimicrobiana. O emprego desses filmes em carne de porco mostrou que a qualidade da carne foi mantida por 15 dias, a $4{ }^{\circ} \mathrm{C}$, enquanto os filmes puros mantiveram a qualidade por apenas 9 dias, mostrando o aumento da vida útil dos produtos, quando utulizados os filmes incoporados com os lipossomas contendo óleo essencial e nanopartículas de prata.

\section{CONSIDERAÇÕES FINAIS}

A versatilidade da utilização dos óleos essenciais na industria de alimentos se deve às suas diversas propriedades, como antimicrobianas e antioxidantes. Estudos mostram que os óleos essenciais vêm sendo aplicados em sucos,embalagens, pães, productos cárneos e lácteos, mostrando uma ampla gama de aplicação no setor alimentício. Porém, os óleos essencias possuem algunas limitações, como intabildiade à luz, oxigênio, serem insolúveis em agua e sabor e odor característicos. Assim, alternativas para suprir esas limitações vêm sendo estudadas, como o emprego de encapsulação, nanoemulsão e lipossomas, que melhoram a estabiliade, permitem uma liberação controlada e evitam perdas da qualidade dessse óleos quando estão sobre presença de luz, calor e umidade. A utilização dessas tecnologias permitem ainda mais aumentar o leque de aplicação desses óleos essenciais nos alimentos, além de gerar valor agregado aos produtos em que são incorporados, uma vez que são produtos naturais, e também por serem considerados alternativas ao uso de atiditvos sintéticos tradicionais. Outra vangem da utilização dessas metodologias é o aumento da vida útil dos produtos alimenticios em que são incorporados os óleos essenciais nanoemulsionados, 
nanoencapsulados e encapsulados em liposomas.

\section{REFERÊNCIAS}

BEDOYA-SERNA, C. M.; DACANAL, G. C.; FERNANDES, A. M.; PINHO, S. C. Antifungal activity of nanoemulsions encapsulating oregano (Origanum vulgare) essential oil: in vitro study and application in Minas Padrão cheese. Brazilian journal of microbiology, v. 49, n. 4, p. 929-935, 2018.

BORGES, R. S.; ORTIZ, B. L. S.; PEREIRA, A. C. M.; KEITA, H.; CARVALHO, J. C. T. Rosmarinus officinalis essential oil: A review of its phytochemistry, anti-inflammatory activity, and mechanisms of action involved. Journal of ethnopharmacology, v. 229, p. 2945, 2019.

BOZIN, B.; MIMICA-DUKIC, N.; SAMOJLIK, I.; JOVIN, E. Antimicrobial and antioxidant properties of rosemary and sage (Rosmarinus officinalis L. and Salvia officinalis L., Lamiaceae) essential oils. Journal of agricultural and food chemistry, v. 55, n. 19, p. 7879$7885,2007$.

CHÁVEZ-GONZÁLEZ, M. L.; RODRÍGUEZ-HERRERA, R.; AGUILAR, C. N. (2016). Essential oils: A natural alternative to combat antibiotics resistance. Antibiotic ResistanceMechanisms and New Antimicrobial Approaches; Kon, K., Rai, M., Eds, p. 227-237.

CUTILlAS, A. B.; CARRASCO, A.; MARTINEZ-GUTIERREZ, R.; TOMAS, V.; TUDELA, J. Rosmarinus officinalis L. essential oils from Spain: composition, antioxidant capacity, lipoxygenase and acetylcholinesterase inhibitory capacities, and antimicrobial activities. Plant Biosystems-An International Journal Dealing with all Aspects of Plant Biology, v. 152, n. 6, p. 1282-1292, 2018.

DAI, J.; LI, C.; CUI, H.; LIN, L. Unraveling the anti-bacterial mechanism of Litsea cubeba essential oil against E. coli O157: H7 and its application in vegetable juices. International Journal of Food Microbiology, 338, 2021.

DE MATOS, S. P.; TEIXEIRA, H. F.; DE LIMA, Á. A.; VEIGA-JUNIOR, V. F.; KOESTER, L. S. Essential oils and isolated terpenes in nanosystems designed for topical administration: A review. Biomolecules, v.9, n. 4, p. 138, 2019.

DEWI, G.; NAIR, D. V.; PEICHEL, C.; JOHNSON, T. J.; NOLL, S.; JOHNY, A. K. Effect of lemongrass essential oil against multidrug-resistant Salmonella Heidelberg and its attachment to chicken skin and meat. Poultry Science, 2021.

DIMA, C.; DIMA, S. Essential oils in foods: extraction, stabilization, and toxicity. Current Opinion in Food Science, v. 5, p. 29-35, 2015.

DIMOPOULOS, G.; KATSIMICHAS, A.; TSIMOGIANNIS, D.; OREOPOULOU, V.; TAOUKIS, P. Cell permeabilization processes for improved encapsulation of oregano essential oil in yeast cells. Journal of Food Engineering, v. 294, 2021.

DOLEA, D.; RIZO, A.; FUENTES, A.; BARAT, J. M.; FERNÁNDEZ-SEGOVIA, I. Effect 
of thyme and oregano essential oils on the shelf life of salmon and seaweed burgers. Food Science and Technology International, v. 24, n. 5, p. 394-403, 2018.

FALLEH, H.; JEMAA, M. B.; SAADA, M.; KSOURI, R. Essential oils: A promising ecofriendly food preservative. Food Chemistry, v. 330, 2020.

FANCELlO, F.; PETRETTO, G. L.; MARCEDDU, S.; VENDITTI, T.; PINTORE, G.; ZARA, G.; ZARA, S. Antimicrobial activity of gaseous Citrus limon var pompia leaf essential oil against Listeria monocytogenes on ricotta salata cheese. Food microbiology, v. $87,2020$.

FRAJ, A.; JAÂFAR, F.; MARTI, M.; CODERCH, L.; LADHARI, N. A comparative study of oregano (Origanum vulgare L.) essential oil-based polycaprolactone nanocapsules/microspheres: Preparation, physicochemical characterization, and storage stability. Industrial Crops and Products, v. 140, 2019.

HASANI-JAVANMARDI, M.; FALLAH, A. A.; ABBASVALI, M. Effect of safflower oil nanoemulsion and cumin essential oil combined with oxygen absorber packaging on the quality and shelf-life of refrigerated lamb loins. LWT, 2021.

HASSOUN, A.; ÇOBAN, Ö. E. Essential oils for antimicrobial and antioxidant applications in fish and other seafood products. Trends in Food Science \& Technology, v. 68, p. 26-36, 2017.

HUANG, L.; WANG, Y.; LI, R.; WANG, Q.; DONG, J.; WANG, J.; LU, S. (2021). Thyme essential oil and sausage diameter effects on biogenic amine formation and microbiological load in smoked horse meat sausage. Food Bioscience, v. 40, 2021.

KSOUDA, G.; SELLIMI, S.; MERLIER, F.; FALCIMAIGNE-CORDIN, A.; THOMASSET, B.; NASRI, M.; HAJJI, M. Composition, antibacterial and antioxidant activities of Pimpinella saxifraga essential oil and application to cheese preservation as coating additive. Food chemistry, v. 288, p. 47-56, 2019.

Liu, W.: Hou, Y.; Jin, Y.; Wang, Y.; Xu, X.; Han, J. Research progress on liposomes: Application in food, digestion behavior and absorption mechanism. Trends in Food Science \& Technology, v. 104, p. 177-189, 2020.

LIU, X.; CHEN, L.; KANG, Y.; HE, D.; YANG, B.; WU, K. Cinnamon essential oil nanoemulsions by high-pressure homogenization: Formulation, stability, and antimicrobial activity. LWT, 2021.

OZAKI, M. M.; DOS SANTOS, M.; RIBEIRO, W. O.; DE AZAMBUJA FERREIRA, N. C.; PICONE, C. S. F.; DOMÍNGUEZ, R.; POLLONIO, M. A. R. Radish powder and oregano essential oil as nitrite substitutes in fermented cooked sausages. Food Research International, v. 140, 2021.

PATEIRO, M.; BARBA, F. J.; DOMÍNGUEZ, R.; SANT'ANA, A. S.; KHANEGHAH, A. M.; GAVAHIAN, M.; LORENZO, J. M. Essential oils as natural additives to prevent oxidation reactions in meat and meat products: A review. Food Research International, v. 113, p. 156-166, 2018. 
PATEIRO, M.; MUNEKATA, P. E.; SANT'ANA, A. S.; DOMÍNGUEZ, R.; RODRÍGUEZLÁZARO, D.; LORENZO, J. M. Application of essential oils as antimicrobial agents against spoilage and pathogenic microorganisms in meat products. International Journal of Food Microbiology, v. 337, 2021.

PIMENTEL-MORAL, S.; VERARDO, V.; ROBERT, P.; SEGURA-CARRETERO, A.; MARTÍNEZ-FÉREZ, A. Nanoencapsulation strategies applied to maximize target delivery of intact polyphenols. Encapsulations, v. 2, p. 559-595, 2016.

PINELli, J. J.; DE ABREU MARTINS, H. H.; GUIMARÃES, A. S.; ISIDORO, S. R.; GONÇALVES, M. C.; DE MORAES, T. S. J.; PICCOLI, R. H. Essential oil nanoemulsions for the control of Clostridium sporogenes in cooked meat product: An alternative? LWT, v. $143,2021$.

PRAKASH, A.; BASKARAN, R.; PARAMASIVAM, N.; VADIVEL, V. Essential oil based nanoemulsions to improve the microbial quality of minimally processed fruits and vegetables: A review. Food Research International, v. 111, p. 509-523, 2018.

RADÜNZ, M.; DA TRINDADE, M. L. M.; CAMARGO, T. M.; RADÜNZ, A. L.; BORGES, C. D.; GANDRA, E. A.; HELBIG, E. Antimicrobial and antioxidant activity of unencapsulated and encapsulated clove (Syzygium aromaticum, L.) essential oil. Food chemistry, v. 276, p. 180-186, 2019.

RAO, J.; CHEN, B.; MCCLEMENTES, D. J. Improving the Efficacy of Essential Oils as Antimicrobials in Foods: Mechanisms of Action. Annual Review Food Science Technology, v.25, n. 10, p. 365-387, 2019.

RAZOLA-DÍAZ, M., D. C.; GUERRA-HERNÁNDEZ, E. J.; GARCÍA-VILLANOVA, B.; VERARDO, V. Recent developments in extraction and encapsulation techniques of orange essential oil. Food Chemistry, v. 354, 2021.

RIBEIRO-SANTOS, R.; ANDRADE, M.; DE MELO, N. R.; SANCHES-SILVA, A. Use of essential oils in active food packaging: Recent advances and future trends. Trends in food science \& technology, v. 61, p. 132-140, 2017.

RIBEIRO-SANTOS, R.; ANDRADE, M.; SANCHES-SILVA, A.; DE MELO, N. R. Essential oils for food application: natural substances with established biological activities. Food and bioprocess technology, v. 11, n. 1, p. 43-71, 2018.

ROSA, C. G.; DE MELO, A. P. Z.; SGANZERLA, W. G.; MACHADO, M. H.; NUNES, M. R.; MACIEL, M. V. D. O. B.; BARRETO, P. L. M. Application in situ of zein nanocapsules loaded with Origanum vulgare Linneus and Thymus vulgaris as a preservative in bread. Food Hydrocolloids, v. 99, 2020.

SÁNCHEZ, R. A. S.; PORTILLO-RUIZ, M. C.; VIRAMONTES-RAMOS, S.; MUÑOZ-CASTELLANOS, L. N.; NEVÁREZ-MOORILLÓN, G. V. Effect of Mexican Oregano (Lippia berlandieri Schauer) Essential Oil Fractions on the Growth of A spergillus spp. in a Bread Model System. Journal of Food Processing and Preservation, v. 39, n. 6, p. 776-783, 2015. 
SÁNCHEZ-RUBIO， M.; TABOADA-RODRÍGUEZ，A.; CAVA-RODA， R.; LÓPEZMOLINA, D.; MARÍN-INIESTA, F. Combined use of thermo-ultrasound and cinnamon leaf essential oil to inactivate Saccharomyces cerevisiae in culture broth and natural orange juice. Journal of food science and technology, v. 55, n. 11, p. 4623-4633, 2018.

SARIKURKCU, C.; ZENGIN, G.; OSKAY, M.; UYSAL, S.; CEYLAN, R.; AKTUMSEK, A. Composition, antioxidant, antimicrobial and enzyme inhibition activities of two Origanum vulgare subspecies (subsp. vulgare and subsp. hirtum) essential oils. Industrial Crops and Products, v. 70, p. 178-184, 2015.

SHARMA, S.; BARKAUSKAITE, S.; JAISWAL, A. K.; JAISWAL, S. Essential oils as additives in active food packaging. Food Chemistry, v. 343, 2020.

SIMÕES, C. M. D. O. et al. Farmacognosia: do produto natural ao medicamento. Porto Alegre: Artmed, 2017.

ŠOJIĆ, B.; PAVLIĆ, B.; TOMOVIĆ, V.; KOCIĆ-TANACKOV, S.; ĐUROVIĆ, S.; ZEKOVIĆ, Z.; ŠKALJAC, S. Tomato pomace extract and organic peppermint essential oil as effective sodium nitrite replacement in cooked pork sausages. Food Chemistry, v. 330, 2020.

STEVANOVIĆ, Z. D.; BOŠNJAK-NEUMÜLlER, J.; PAJIĆ-LIJAKOVIĆ, I.; RAJ, J.; VASILJEVIĆ, M. Essential oils as feed additives-future perspectives. Molecules, v. 23, n. 7, 2018.

SUN, X.; WANG, J.; ZHANG, H.; DONG, M.; LI, L.; JIA, P.; WANG, L. Development of functional gelatin-based composite films incorporating oil-in-water lavender essential oil nano-emulsions: Effects on physicochemical properties and cherry tomatoes preservation. LWT, v. 142, 2021.

WU, Z.; ZHOU, W.; PANG, C.; DENG, W.; XU, C.; WANG, X. Multifunctional chitosanbased coating with liposomes containing laurel essential oils and nanosilver for pork preservation. Food Chemistry, v. 295, p. 16-25, 2019. 